\title{
Tritium radioactive labeling of detonation nanodiamonds
}

\author{
Hugues A. Girard ${ }^{(a)}$, Abdelouahab El-Kharbachi ${ }^{(b)}$, Sébastien Garcia-Argote ${ }^{((b)}$, Tristan Petit ${ }^{(a)}$, Philippe

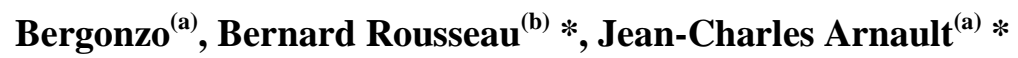

\author{
Received (in $X X X, X X X$ ) Xth $X X X X X X X X X 20 X X$, Accepted Xth $X X X X X X X X X 20 X X$ \\ ${ }_{5}$ DOI: 10.1039/b000000x
}

For the first time, the radioactive labeling of detonation nanodiamonds was efficiently achieved using a tritium microwave plasma. According to our measurements, the total radioactivity reaches $9120 \pm 120 \square \mathrm{Ci} / \mathrm{mg}$, with $93 \%$ of $3 \mathrm{H}$ 10 atoms tightly bonded to the surface and up to $7 \%$ embedded into the diamond core. Such $3 H$ doping will ensure highly stable radiolabeled nanodiamonds, on which surface functionalization is still allowed. This breakthrough opens the way to biodistribution and pharmacokinetics studies of 15 nanodiamonds, while this approach can be scalable to easily treat bulk quantities of nanodiamonds at low cost.

Nanodiamonds (NDs) possess several essential assets for biomedical applications: a very weak cytotoxicity and 20 genetoxicity $^{1-4}$, a carbon-related surface chemistry allowing covalent functionalization for targeting or labeling (oligonucleotides, proteins, fluorescent dyes...) ${ }^{5,6}$ and a tunable surface charge for drug adsorption ${ }^{7,8}$. Detonation nanodiamonds synthetized by explosion ${ }^{9}$ combine all this possibilities in a 25 primary size of $5 \mathrm{~nm}$, compatible with kidney filtration for an expected easier elimination ${ }^{10}$.

Nevertheless, the prerequisite to any therapeutic applications of NDs vector is the assessment of its toxicity, tissue distribution and elimination. While NDs are now recognized as well tolerated 30 by organisms ${ }^{11,12}$, there are still contradictory results regarding their tissue distribution and clearance ${ }^{13,14}$. Nanoparticle radiotracers are currently widely used to assess quantitatively the health hazard related to nanotechnologies or as theranostic agents

${ }^{15}$. In the former studies, NDs biodistribution in small animal was 35 inferred from the signal of radiotracers as ${ }^{18} \mathrm{~F}{ }^{16},{ }^{188} \mathrm{Re}{ }^{17}$ or dyes ${ }^{18}$ chemically grafted. However, these labels are likely to be separated from NDs during their transit in the animal body and unable from any further functionalization. As such radioactive labeling of the diamond core itself appears as a promising ${ }_{40}$ "tritium probe" approach that ensures the NDs tracing for biolabeling or biodistribution investigations. Although tritium labeling was previously mentioned ${ }^{19}$, such a direct radioactive labeling using plasma treatment has not been proposed yet.

We report here the radiolabeling of detonation nanodiamonds 45 with tritium. Tritium labeling is routinely used for biodistribution studies, for example of paclitaxel encapsulated nanoparticles ${ }^{20}$ or squalenoyl nanomedicine $\mathrm{e}^{21} \cdot{ }^{3} \mathrm{H}$ label was also introduced into a drug component to monitor its release by pharmacokinetics studies ${ }^{22}$. Indeed, tritium is a $\beta^{-}$emitter, which decays into ${ }^{3} \mathrm{He}$, 50 with a 12.32 years half-life and an average $5.7 \mathrm{keV}$ kinetic energy of the beta particle. Tritium is easily detectable from standard This journal is (C) The Royal Society of Chemistry [year] liquid scintillation counting and autoradiography. In case of stable insertion onto ND vector, the biodistribution will not be affected by tritium labeling and the potential risk of the in vivo ${ }_{55}$ formation of ${ }^{3} \mathrm{H}_{2} \mathrm{O}$ would be avoided ${ }^{23}$.

Our original approach is based on a microwave (MW) plasma treatment in order to label nanodiamonds with ${ }^{3} \mathrm{H}$ atoms. This experimental technique was previously applied to efficiently hydrogenate detonation NDs 24,25 and rely on the hydrogen 60 plasma exposure of NDs contained in a quartz pipe. Hundreds of milligrams of NDs can be treated at the same time, resulting in fully hydrogenated NDs (H-NDs). Using this approach, the formation of $\mathrm{C}-{ }^{1} \mathrm{H}$ bonds at the ND surface has already been evidenced via different spectroscopic techniques (XPS, FTIR, ${ }_{65}$ Raman) as reported elsewhere ${ }^{7,25,24}$. We also demonstrated specific surface properties of ${ }^{1} \mathrm{H}-\mathrm{NDs}$ leading to positive Zeta potential in water suspension related to their high affinity toward water molecules ${ }^{7}$. Note that hydrogen diffusion in the ND core is also expected, as it occurs in bulk diamond under similar plasma 70 conditions ${ }^{26,27}$. We thus propose here to apply this approach to incorporate ${ }^{3} \mathrm{H}$ on the surface and/or in the bulk of nanodiamonds for their subsequent labeling.

Detonation NDs provided by Nanocarbon Research Institute (Japan) were exposed to microwave (MW) tritium plasma using 75 the experimental MW plasma set-up described elsewhere ${ }^{25}$. The quartz tube was loaded with $17 \mathrm{mg}$ of NDs and then connected to the pumping system and gas inlet. Tritium was then introduced in the tube up to a pressure of 9 mbar, i.e. $6.10^{-6}$ moles. After a first exposure of $5 \mathrm{~min}$ using a $140 \mathrm{~W}$ injected MW power, oxygen80 related species desorbed from the NDs during this first plasma treatment were purged by renewing the tritium gas (still 9 mbar). A second plasma exposure of $12 \mathrm{~min}$ at $140 \mathrm{~W}$ was then applied. NDs were cooled down in tritium gas, before being poured into methanol $(5 \mathrm{~mL})$. After agitation, the solvent was evaporated. 85 The cleaning operation was repeated twice to allow complete removal of labile tritium. Treated NDs were then stored as dry powder under ambient atmosphere. Considering the two loadings of tritium gas at 9 mbars, an internal volume of the quartz tube of $15.8 \mathrm{~mL}$, and a mean activity of the tritium gas of $58000 \mathrm{Ci} / \mathrm{mol}$, 90 calculations reveal that the $17 \mathrm{mg}$ of NDs were finally exposed to a total activity of $696 \mathrm{mCi}$.

Quantification of ${ }^{3} \mathrm{H}$ incorporation was performed by measuring the radioactivity in the combustion gas of air-annealed ${ }^{3} \mathrm{H}$-plasma exposed NDs, using liquid scintillation. To identify the diverse 95 tritium binding states, radioactivity countings were done at different desorption isotherms with long stabilization times (20 h). The radioactivity release from $5 \mathrm{mg}{ }^{3} \mathrm{H}-\mathrm{NDs}$ according to the temperature threshold and its associated kinetic are shown on [journal], [year], [vol], 00-00|1 
Figure 1. At room temperature, no significant tritium desorption in ambient atmosphere was observed. After $4 \mathrm{~h}$ at $160^{\circ} \mathrm{C}$, only 500 $\mu \mathrm{Ci} / \mathrm{mg}$ were measured in the combustion gas, which rise to 940 $\mu \mathrm{Ci} / \mathrm{mg}$ after $20 \mathrm{~h}$ at the same temperature. This concentration 5 represents around $10 \%$ of the total radioactivity carried by the treated NDs. At these temperatures, desorption only affect the weakly bonded molecules to the NDs surface (electrostatic adsorption, hydrogen bonds, etc...). Nevertheless, this observation is of outmost importance as it confirms the stability 10 of the association of ${ }^{3} \mathrm{H}$ with NDs for further biological assays. After a following step at $400^{\circ} \mathrm{C}$ for an additional $20 \mathrm{~h}$, $7630 \mu \mathrm{Ci} / \mathrm{mg}$ were released, i.e. corresponding to $83 \%$ of the total radioactivity. At this temperature threshold, a strong oxidation occurs with the formation of carbonyls and carboxylic groups 28

15 and covalent surface terminations are desorbed. This observation confirms that the major part of tritium labelling can be associated with ${ }^{3} \mathrm{H}$ strongly bonded at the surface of the NDs. However, part of the radioactivity still remains in the diamond core that can be released after a final annealing at $600^{\circ} \mathrm{C}$, a temperature at 20 which NDs are entirely burned away. Accordingly, the total radioactive activity of ${ }^{3} \mathrm{H}-\mathrm{ND}$ s is estimated to $9120 \pm 120 \mu \mathrm{Ci} / \mathrm{mg}$. From these data, we inferred that this stable radioactive labeling of ND not only results from surface $\mathrm{C}-{ }^{3} \mathrm{H}$ bonds but also from the diffusion of ${ }^{3} \mathrm{H}$ deep inside the diamond lattice. The total 25 subsequent activity released during the $160^{\circ} \mathrm{C}$ and $400^{\circ} \mathrm{C}$ annealings enable to estimate that $93 \%$ of the tritium atoms were bound to the ND surface, thus $7 \%$ are buried in the diamond core. This indicates that the tritium diffusion within the diamond matrix is active during this treatment as was previously reported 30 for hydrogen in bulk diamond ${ }^{26,27}$. Furthermore, this embedded ${ }^{3} \mathrm{H}$ represents a major advantage in the particular case of surface functionalization of ${ }^{3} \mathrm{H}-\mathrm{ND}$, that would have led to the total or partial replacement of $\mathrm{C}^{-}{ }^{3} \mathrm{H}$ surface terminations. Part of the tritium being implanted within the nanodiamond lattice, $\beta^{-}$

35 activity measurement will thus be directly related to ND concentration, allowing accurate ND quantification in tissues. Indeed, pharmacokinetic studies can be carried out with a total activity of only $1 \mu \mathrm{Ci}$ per mice, as reported in Couvreur et al. paper ${ }^{21}$. Thus, with more than $600 \mu \mathrm{Ci} / \mathrm{mg}$ remaining in the 40 particle core even after complete surface oxidation, our ${ }^{3} \mathrm{H}-\mathrm{NDs}$ will perfectly match the biodistribution requirements in terms of activities and concentration. Furthermore, beyond the synthesis of radioactive labeled NDs for biological application, these experiments also reveal the very high loading capacity of NDs 45 with tritium, and consequently with hydrogen. Starting from 696 $\mathrm{mCi}$ injected in the quartz tube, desorption treatments demonstrates that the $17 \mathrm{mg}$ of treated NDs finally exhibit a total activity of $155 \mathrm{mCi}$, i.e. an incorporation yield of $22 \%$. Obviously, this high adsorption capacity is directly linked with 50 the specific surface area of our nanomaterial. Considering a value of $350 \mathrm{~m}^{2} / \mathrm{g}$ we measured ${ }^{7}$ and $17 \mathrm{mg}$ of NDs, a mean density of $5.10^{13}{ }^{3} \mathrm{H} / \mathrm{cm}^{2}$ is obtained for tritium concentration at NDs surface. As a comparison, note that the hydrogen concentration obtained on a $2 \times 1$ reconstructed (100) diamond surface saturated 55 with hydrogen ${ }^{29}$ is $1.10^{15} \mathrm{H} / \mathrm{cm}^{2}$. This means that, despite harsh plasma conditions to modify their surface, only 1 carbon atom over 20 seems to be linked to tritium on our NDs. Here, the effectiveness of such plasma treatments on NDs and certainly on NDs aggregates requires further investigation. However, this ${ }_{60}$ result appears as essential to better understand the surface reactivity of NDs, while hydrogenation of nanodiamonds focuses an intense research effort notably toward photocatalysis application as recently reported in Hamers ${ }^{30}$ and Nebel ${ }^{31}$ papers.

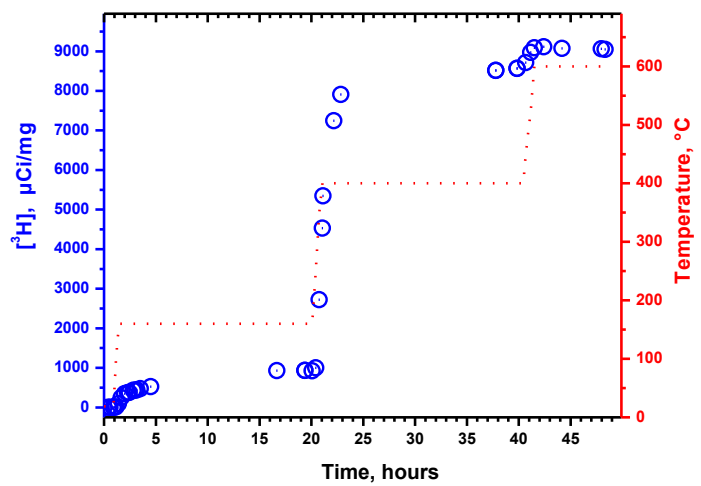

Figure 1. Radioactive titration of tritium released from ${ }^{3} \mathrm{H}-\mathrm{NDs}$ (blue 75 circles: Experimental. points) after three sequential annealing treatments in air at increasing temperatures. The dotted red line indicates the temperature measured in the crucible.

The surface chemistry of ${ }^{3} \mathrm{H}-\mathrm{ND}$ s was characterized using FTIR spectroscopy. Using a similar approach as previously reported for 80 conventional hydrogenated NDs preparation, here ${ }^{3} \mathrm{H}-\mathrm{NDs}$ were incorporated in a $\mathrm{KBr}$ pellet $(2 \% \mathrm{wt})$ for transmission analysis. FTIR spectra of as-received NDs and ${ }^{3} \mathrm{H}-\mathrm{NDs}$ are reported in Figure 2. Both samples exhibit strong features at 3400 and 1630 $\mathrm{cm}^{-1}$ which originate from adsorbed water in the $\mathrm{KBr}$ pellet and 85 on NDs ${ }^{28}$ and a contamination with $\mathrm{CO}_{2}$ around $2375 \mathrm{~cm}^{-1}$. Note that due to the radioactivity of the sample, the in-situ annealing of the $\mathrm{KBr}$ pellet we usually performed to remove this adsorbed water was not applied here. An additional feature is also visible around 2160 which is not attributed yet. As-received NDs exhibit 90 a characteristic $\mathrm{C}=\mathrm{O}$ stretching band at $1720 \mathrm{~cm}^{-1}$, linked to carbonyl and/or carboxylic groups ${ }^{32}$. C-H stretching are also clearly visible around $2900 \mathrm{~cm}^{-1}$, typical signature of amorphous carbon adsorbed on the nanodiamond. After treatment, the disappearance of the $\mathrm{C}=\mathrm{O}$ stretching band at $1720 \mathrm{~cm}^{-1}$ confirms 95 the desorption of the oxidized terminations during the ${ }^{3} \mathrm{H}$-plasma exposure. This is in agreement with our previous plasma hydrogenation studies ${ }^{24,33}$. Surprisingly, C-H features do not disappear after ${ }^{3} \mathrm{H}$-plasma treatment. In fact, a part of this $\mathrm{C}-\mathrm{H}$ stretching band could result from organic contamination of the 100 sample ${ }^{34}$, although it can also be assumed that some C-H terminations remain on NDs even after such H-plasma treatment. Concerning the formation of such $\mathrm{C}-{ }^{3} \mathrm{H}$ stretching bands, FTIR experiments with ${ }^{3} \mathrm{H}$ are poorly described in the literature. Based on Sun and Sidhu works ${ }^{35,36}$, we calculated the $\mathrm{C}^{3} \mathrm{H}$ stretching ${ }_{105}$ frequencies with respect to $\mathrm{C}-{ }^{1} \mathrm{H}$ bands using harmonic potential approximation and reduced mass ratios (equation 1): in our case, a ratio of 0.62 is obtained, which leads to a $\mathrm{C}-{ }^{3} \mathrm{H}$ stretching most likely to be localized around $1800 \mathrm{~cm}^{-1}$. On the observed FTIR spectrum, no clear features are visible around such wavenumbers 110 after ${ }^{3} \mathrm{H}$ treatment, which is not at first glance in agreement with the creation of $\mathrm{C}^{3} \mathrm{H}$ terminations. However, as explained by Sidhu et al. ${ }^{36}$, a very weak signal intensity of the $\mathrm{C}-{ }^{3} \mathrm{H}$ stretching bands is expected, since the integrated intensity is inversely proportional to the reduced mass of the oscillator. Moreover, 115 tritium coverage represents $5 \%$ of the carbon atoms. Here, a clear spectroscopic evidence of the formation of $\mathrm{C}-{ }^{3} \mathrm{H}$ terminations after our ${ }^{3} \mathrm{H}$-plasma treatment is thus not allowed. Nevertheless, the desorption of the carboxylic functions revealed by FTIR , which proves the reactivity of the ${ }^{3} \mathrm{H}$ plasma together with the 120 stable radioactivity observed up to $400^{\circ} \mathrm{C}$ of our treated NDs definitely support the formation of such $\mathrm{C}_{-}^{3} \mathrm{H}$ terminations. 


$$
\frac{\omega_{C_{-} T}}{\omega_{C_{-} H}}=\sqrt{\frac{m_{H}\left(m_{T}+M_{C}\right)}{m_{T}\left(m_{H}+M_{C}\right)}}
$$

equation (1)

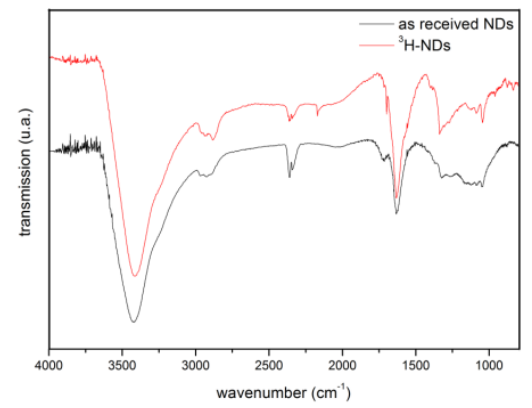

Figure 2 FTIR spectrum of ${ }^{3} \mathrm{H}-\mathrm{NDs}$ compared to as received NDs

In conclusion, we reported here for the first time a very 5 straightforward, efficient and scalable approach enabling radiolabeling of NDs using tritium MW plasma. The results demonstrate the excellent stability of tritium incorporated into NDs which can be even diffusing through the inner core of the particles. A major advantage of this approach rely in the 10 possibility to keep a high activity concentration in the ND core, suitable for biodistribution studies, which will remains unaffected even after subsequent functionalization of the ND surface. While such $\beta$ - activity will be directly related to $3 \mathrm{H}-\mathrm{ND}$ s concentration, this powerful approach to produce radiolabeled NDs in large 15 quantity (up to hundreds of $\mathrm{mg}$ ) does now appear as a very efficient tool to evaluate the biodistribution and the pharmacokinetics studies of nanodiamonds in tissues.

\section{Notes and references}

${ }^{a}$ CEA, LIST, Diamond Sensors Laboratory, F-91191 Gif-sur20 Yvette, France.*E-mail: jean-charles.arnault@cea.fr

${ }^{b}$ CEA, iBiTec-S, Tritium Labeling Laboratory, F-91191 Gif-surYvette, France. * E-mail: bernard.rousseau@cea.fr

1.V. Paget, J. A. Sergent, R. Grall, S. Altmeyer-Morel, H. A. ${ }_{25}$ Girard, T. Petit, C. Gesset, M. Mermoux, P. Bergonzo, J. C. Arnault, and S. Chevillard, Nanotoxicology, 2013, 1-11. 2.S.-J. Yu, M.-W. Kang, H.-C. Chang, K.-M. Chen, and Y.-C. Yu, J. Am. Chem. Soc., 2005, 127, 17604-17605.

3.A. M. Schrand, H. Huang, C. Carlson, J. J. Schlager, E. Ōsawa, ${ }_{30}$ S. M. Hussain, and L. Dai, J. Phys. Chem. B, 2007, 111, $2-7$. 4.N. Mohan, C.-S. Chen, H.-H. Hsieh, Y.-C. Wu, and H.-C. Chang, Nano Lett., 2010, 10, 3692-3699.

5.A. Krueger and D. Lang, Adv. Funct. Mater., 2012, 22, 890906.

35 6.A. H. Smith, E. M. Robinson, X.-Q. Zhang, E. K. Chow, Y. Lin, E. Osawa, J. Xi, and D. Ho, Nanoscale, 2011, 3, 2844-2848. 7.T. Petit, H. a Girard, A. Trouvé, I. Batonneau-Gener, P. Bergonzo, and J.-C. Arnault, Nanoscale, 2013, 1-5. 8.T. Petit, J. C. Arnault, H. A. Girard, M. Sennour, T.-Y. Kang, ${ }_{40}$ C.-L. Cheng, and P. Bergonzo, Nanoscale, 2012, 4, 6792 - 6799. 9.V. Y. Dolmatov, Russ. Chem. Rev., 2007, 76, 339-360. 10.H. S. Choi, W. Liu, P. Misra, E. Tanaka, J. P. Zimmer, B. Itty Ipe, M. G. Bawendi, and J. V Frangioni, Nat. Biotechnol., 2007, 25, 1165-70.
45 11.A. P. Puzyr, A. V. Baron, K. V. Purtov, E. V. Bortnikov, N. N. Skobelev, O. a. Mogilnaya, and V. S. Bondar, Diam. Relat. Mater., 2007, 16, 2124-2128.

12.A. M. Schrand, S. a. C. Hens, and O. A. Shenderova, Crit. Rev. Solid State Mater. Sci., 2009, 34, 18-74.

50 13.Y. Zhu, J. Li, W. Li, Y. Zhang, X. Yang, N. Chen, Y. Sun, Y. Zhao, C. Fan, and Q. Huang, Theranostics, 2012, 2, 302-12.

14.Y. Yuan, Y. Chen, J.-H. Liu, H. Wang, and Y. Liu, Diam. Relat. Mater., 2009, 18, 95-100.

15.H. Hong, Y. Zhang, J. Sun, and W. Cai, Nano Today, 2009, 4, 55 399-413.

16.S. Rojas, J. D. Gispert, R. Martin, S. Abad, C. Menchón, D. Pareto, V. M. Víctor, M. Alvaro, H. Garcia, and J. R. Herance, ACS Nano, 2011, null.

17.X. Zhang, J. Yin, C. Kang, J. Li, Y. Zhu, W. Li, Q. Huang, 60 and Z. Zhu, Toxicol. Lett., 2010, 198, 237-43.

18.E. K. Chow, X.-Q. Zhang, M. Chen, R. Lam, E. Robinson, H. Huang, D. Schaffer, E. Osawa, A. Goga, and D. Ho, Sci. Transl. Med., 2011, 3, 73ra21.

19.M. Chernysheva, I. Myasnikov, and G. Badun, Mendeleev ${ }_{65}$ Commun., 2012, 290-291.

20.D. Shenoy, S. Little, R. Langer, and M. Amiji, Pharm. Res., 2005, 22, 2107-14.

21.L. H. Reddy, H. Khoury, A. Paci, A. Deroussent, H. Ferreira,

C. Dubernet, X. Declèves, M. Besnard, H. Chacun, S. Lepêtre-

70 Mouelhi, D. Desmaële, B. Rousseau, C. Laugier, J.-C. Cintrat, G.

Vassal, and P. Couvreur, Drug Metab. Dispos. , 2008, 36 , 15701577.

22.H. Xie, C. Audette, M. Hoffee, J. M. Lambert, and W. A. Blättler, J. Pharmacol. Exp. Ther. , 2004, 308 , 1073-1082.

75 23.C. Shaffer and M. Gunduz, Drug Metab, 2006, 34, 16151623.

24.H. A. Girard, T. Petit, S. Perruchas, T. Gacoin, C. Gesset, J. C. Arnault, and P. Bergonzo, Phys. Chem. Chem. Phys., 2011, 13, $11517-11523$.

80 25.H. A. Girard, J. C. Arnault, S. Perruchas, S. Saada, T. Gacoin, J.-P. Boilot, and P. Bergonzo, Diam. Relat. Mater., 2010, 19, 1117-1123.

26.D. Ballutaud, T. Kociniewski, J. Vigneron, N. Simon, and H. Girard, Diam. Relat. Mater., 2008, 17, 1127-1131.

${ }_{85}$ 27.D. Ballutaud, F. Jomard, T. Kociniewski, E. Rzepka, H. Girard, and S. Saada, Diam. Relat. Mater., 2008, 17, 451-456.

28.O. Shenderova, I. Petrov, J. Walsh, V. Grichko, V. Grishko, T. Tyler, and G. Cunningham, Diam. Relat. Mater., 2006, 15, 17991803.

90 29.H. Yagi, A. Hatta, and T. Ito, Appl. Surf. Sci., 1999, 137, 5056.

30.D. Zhu, L. Zhang, R. E. Ruther, and R. J. Hamers, Nat.

Mater., 2013, 12, 836-41.

31.C. E. Nebel, Nat. Mater., 2013, 12, 780-1.

95 32.J.-S. Tu, E. Perevedentseva, P.-H. Chung, and C.-L. Cheng, J. Chem. Phys., 2006, 125, 174713-174717.

33.J.-C. Arnault, T. Petit, H. Girard, A. Chavanne, C. Gesset, M. Sennour, and M. Chaigneau, Phys. Chem. Chem. Phys., 2011, 13, 11481-11487.

100 34.C.-L. Cheng, C.-F. Chen, W.-C. Shaio, D.-S. Tsai, and K.-H. Chen, Diam. Relat. Mater., 2005, 14, 1455-1462.

35.Y. Sun and J. Chen, J. Phys. Chem. B, 1997, 5647, 70827086.

36.L. Sidhu and T. Kosteski, J. Appl. Phys., 1999, 85, 25741052578. 